\title{
Temporal evolution of changes in left ventricular function induced by cold pressor stimulation An assessment with radionuclide angiography and gold $195 m$
}

\author{
DUNCAN S DYMOND, JOHN L CAPLIN, WILLIAM FLATMAN, PETER BURNETT, * \\ SEAMUS BANIM, ROWORTH SPURRELL
}

From the Departments of Cardiology and Nuclear Medicine, St Bartholomew's Hospital, London

SUMMARY The evolutionary changes in left ventricular function induced by cold pressor stimulation were investigated at 90 second intervals by rapid sequential first pass radionuclide angiography using the short half life tracer gold $195 \mathrm{~m}$. The results in 12 subjects with normal coronary arteries were compared with those in 12 patients with coronary artery disease. Left ventricular ejection fraction fell significantly from resting values in both groups after 1 minute of cold pressor, but only in patients with coronary disease was the significant fall maintained at 2.5 and 4 minutes. In both groups, the maximum decrease in ejection fraction occurred after 1 minute, whereas the maximum rise in systolic blood pressure occurred after 2.5 minutes. New abnormalities of regional ventricular function developed in 10 normal subjects after 1 minute of cold, with a total of 12 new abnormal segments. Only two such segments were seen at the later stages of imaging. Twenty one new segments developed after 1 minute in the coronary disease group, and 13 segments remained abnormal after 4 minutes. Three patients, two of whom had left main stem stenoses, showed persistent abnormalities of ventricular function after 2 minutes of recovery from cold stimulation.

Thus left ventricular function changes rapidly during a period of cold stimulation in both those without and those with coronary disease. When the cold pressor test is used with multiple gated equilibrium imaging, the timing of imaging may be crucial to the results and interpretation of the test. The discordance between functional changes and rise in blood pressure is further evidence that alterations in afterload are not solely responsible for cold induced abnormalities.

Cold pressor stimulation has gained some popularity as a stress test for use with multiple gated equilibrium radionuclide angiographic (MUGA) studies. It has been proposed as a sensitive and specific alternative to dynamic exercise as a way of unmasking abnormalities of left ventricular function in patients with coronary artery disease. ${ }^{1}$ More recently, several reports have challenged the claim that the cold pressor test has equivalent sensitivity and specificity to bicycle exercise and questioned its use as a stress test with MUGA

Requests for reprints to Dr Duncan S Dymond, Cardiac Departs ment, St Bartholomew's Hospital, London EC1A 7BE.

^Current address: St Vincent's Hoopital, Sydney, Australia.

Accepted for publication 29 November 1983 studies. ${ }^{2-5}$ Careful review of these reports indicates that the imaging procedures used differ between institutions, with data acquisition times varying from 2 to 5 minutes. ${ }^{1-4}$ Haemodynamic adaptation to cold stimulation was reported by Greene et al in 1965,6 and it seems possible that left ventricular function could change as haemodynamic responses alter. If ventricular function does not remain stable during the period of cold stimulation, then the results of MUGA studies could vary depending on the timing of acquisition and its relation to haemodynamic changes.

First pass radionuclide angiography provides an ideal way of testing this hypothesis, as acquisition requires only a few cardiac cycles for a few seconds, ${ }^{7}$ but until recently it was not applicable for multiple intervention studies because of the unacceptable radi- 
ation burden imposed by the need for multiple bolus doses of technetium- $99 \mathrm{~m}$. Gold-195m is a radiopharmaceutical with a short half life of only $30.5 \mathrm{~s}$. It has recently been developed and produced in the form of portable mercury $195 \mathrm{~m} /$ gold $195 \mathrm{~m}$ generators for clinical use ${ }^{8}$ and has been shown to be highly suitable for rapid sequential first pass studies in patients since it gives a low radiation exposure. ${ }^{9}$ The purpose of this study, therefore, was to investigate the temporal evolutionary changes in left ventricular function occurring during cold pressor stimulation.

\section{Patients and methods}

Two groups of 12 subjects each were studied. The first group consisted of nine patients (seven men, two women), who had undergone cardiac catheterisation and coronary arteriography for anginal chest pain, atypical chest pain, or positive electrocardiographic stress tests, and who had entirely normal coronary arteriograms. All patients had normal $M$ mode and cross sectional echocardiograms, and one patient had some apical hypokinesis on his contrast left ventriculogram. The mean age of this group was 48 (range 43-53). An additional three healthy male volunteers (aged 28-32 years), who were asymptomatic, non-smoking, and normotensive were studied. All had undergone a maximal symptom limited treadmill exercise test with normal haemodynamic and electrocardiographic responses. The second group consisted of 12 patients (11 men, one woman), with angiographically documented coronary artery disease. All had $\geqslant 50 \%$ reduction of luminal diameter. One patient had single vessel disease, four two vessel disease, five triple vessel disease, and two triple vessel disease with additional lesions in the left main stem. Five patients had a previously documented myocardial infarction, and the mean age of this group was 54 (range 48-64) years. Excluded from the study were patients with unstable angina, those who were not in sinus rhythm, those with valvular, myopathic, or congenital heart disease, and those with left ventricular aneurysms. Consent for the study was obtained from all subjects.

\section{RADIONUCLIDE ANGIOGRAPHY}

Radionuclide angiography was carried out either on the day before or within one week after cardiac catheterisation. No patient received nitrates, calcium antagonists, or beta blocking drugs on the day of the study. All subjects were imaged in the anterior projection while seated using a multicrystal gamma camera. ${ }^{7}$ First pass radionuclide angiograms were obtained with the subjects at rest and after 1, 2.5, and 4 minutes of cold pressor stimulation produced by immersion of one hand in iced water to just above the level of the wrist. A final radionuclide angiogram was obtained after 2 minutes of recovery. For each radionuclide study a $15-20 \mathrm{mCi}(555-740 \mathrm{MBq})$ bolus of gold-195 m was injected in a volume of $<0.5 \mathrm{ml}$. Imaging was carried out for $30 \mathrm{~s}$ at each stage with 30 ms framing intervals. Heart rate and sphygmomanometer cuff arterial blood pressure were measured during the last $15 \mathrm{~s}$ of each imaging stage to coincide as closely as possible with the left ventricular phase of the study.

\section{Data processing}

All data were corrected for instrument dead time and flood field non-uniformity, a uniform mercury 203 source being used for the latter. ${ }^{9}$ Left ventricular ejection fraction was measured from left ventricular time-activity curves as described. ${ }^{7}$ Regional left ventricular function was evaluated from count based regional ejection fraction images which display regional contribution to ejection on a pixel by pixel basis using a 16 colour scale. ${ }^{10}$ Anterior, inferior, and apical segments were judged visually to be abnormal if regional ejection fraction fell below $50 \%$ in a segment, and if the abnormality occupied at least half the segment.

\section{STATISTICAL ANALYSIS}

For each group statistical differences in heart rate, arterial blood pressure, and ejection fraction between rest and the various stages of cold pressor were assessed by a repeated measures analysis of variance. Where a significant $F$ value was obtained differences were further analysed with a paired $t$ test. Analysis of variance was also used to examine differences in the temporal pattern of changes (interaction) between those with and those without coronary disease. Results are expressed as means \pm standard deviation.

\section{Results}

All subjects completed the protocol, and none complained of angina pectoris. Most complained of discomfort in the immersed hand.

\section{HEART RATE}

Changes in heart rate for the two groups are shown in Fig. 1. Mean heart rate in the non-coronary disease group was $71.8 \pm 14.8$ beats/min at rest, rising significantly to $83.8 \pm 18.2$ beats $/ \mathrm{min}$ after 1 minute of cold pressor $(p<0.001)$. It was not significantly different from rest at 2.5 or 4 minutes, although remaining raised. After 2 minutes of recovery the rate was $70.0 \pm 10.7$ beats $/ \mathrm{min}$. In patients with coronary artery disease the heart rate rose from $65.5 \pm 11.4$ beats $/ \mathrm{min}$ at rest to $74.0 \pm 9.8$ beats $/ \mathrm{min}$ at 1 minute $(p<0.001)$. Again, despite remaining raised at 2.5 and 4 minutes, it was not significantly different from the values at rest 

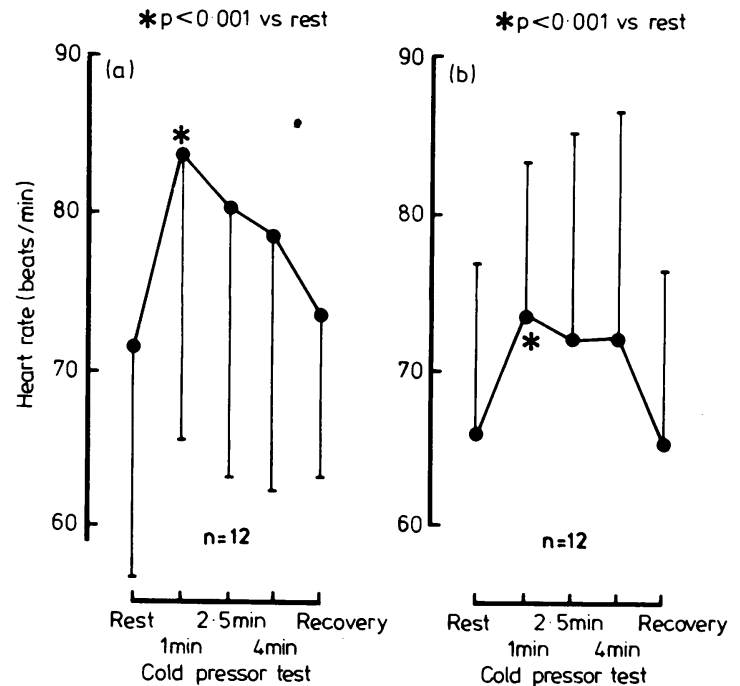

Fig. 1 Mean $( \pm S D)$ heart rate during the stages of cold pressor in (a) subjects with normal coronary arteries and (b) those with coronary disease.

at these stages. After 2 minutes of recovery the heart rate was $65.3 \pm 11.4$ beats $/ \mathrm{min}$.

No differences were observed in the pattern of heart rate response between the two groups.

\section{SYSTOLIC BLOOD PRESSURE}

The response of systolic blood pressure to cold pressor is shown in Fig. 2. Mean systolic pressure in those without coronary disease rose from 130.0 13.9 $\mathrm{mmHg}$ at rest to $140.5 \pm 19.8 \mathrm{mmHg}$ at 1 minute, rising further to $146.0 \pm 21.6 \mathrm{mmHg}$ at 2.5 minutes (both $\mathrm{p}<0.001$ vs rest). Pressure remained significantly raised at 4 minutes, and after 2 minutes' recovery had fallen to $122 \cdot 7 \pm 16.0 \mathrm{mmHg}$. In patients with coro-

$$
\begin{aligned}
* p & <0.001 \text { vs rest } \\
* * * p & <0.05 \text { vs rest }
\end{aligned}
$$
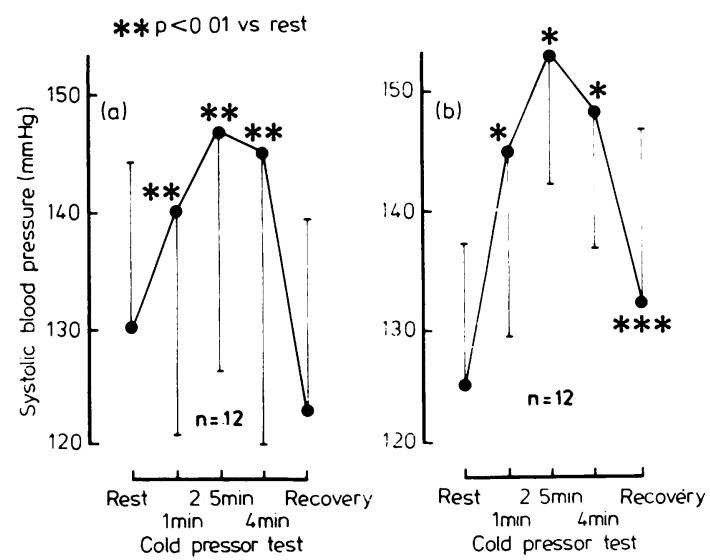

Fig. 2 Mean ( $\pm S D$ ) systolic blood pressure during the stages of cold pressor in (a) subjects with normal coronary arteries and (b) those with coronary disease. nary disease disease pressure rose from $125 \cdot 0 \pm 12 \cdot 4$ $\mathrm{mmHg}$ to $145.0 \pm 13.8 \mathrm{mmHg}$ at 1 minute, rising further to $153.7 \pm 11.9 \mathrm{mmHg}$ at 2.5 minutes (both $\mathrm{p}<0.001$ vs rest). Pressure again remained significantly raised at 4 minutes and although it fell after 2 minutes' recovery, the values remained just significantly higher than at rest with a mean of $132.0 \pm 12.3 \mathrm{mmHg}(\mathrm{p}<0.05)$.

There was no significant difference in the temporal behaviour of blood pressure in those with or those without coronary disease.

\section{EJECTION FRACTION}

Changes in left ventricular ejection fraction for the two groups are shown in Fig. 3. In those without disease the ejection fraction was $61 \cdot 8 \pm 11 \cdot 1 \%$ at rest and fell significantly after 1 minute of cold stimulation to $56.8 \pm 11.2 \%(p<0.005)$. Six of the 12 subjects in this group showed falls of $\geqslant 5 \%$, the largest individual fall being $16 \%$. After 2.5 minutes the mean ejection fraction was $59.5 \pm 8.5 \%$ and was no longer significantly lower than at rest. Only three subjects had values depressed by $5 \%$ or more compared with those at rest. At 4 minutes the mean ejection fraction was $61 \cdot 1 \pm 10.5 \%$ and after recovery $60.5 \pm 9.5 \%$. Two subjects had ejection fractions $\geqslant 5 \%$ lower than those at rest during these two stages. In patients with coronary disease the ejection fraction was $54.2 \pm 8.8 \%$ at rest falling to $45 \cdot 7 \pm 10 \cdot 6 \%$ after 1 minute of cold pressor $(p<0.001)$. In this group, however, the ejection fraction remained significantly depressed at both 2.5 and 4 minutes of cold pressor (mean $48.2 \pm 8.7 \%$ and $48.0 \pm 10.6 \%$ respectively, both $p<0.001$ vs rest). After recovery the mean ejection fraction was $51 \cdot 8 \pm 8 \cdot 6 \%$. Nine patients had falls of $\geqslant 5 \%$ compared with those at rest at 1 minute, seven patients at 2.5 minutes and 4 minutes, and two after recovery.

Despite the persistent depression of ejection frac-

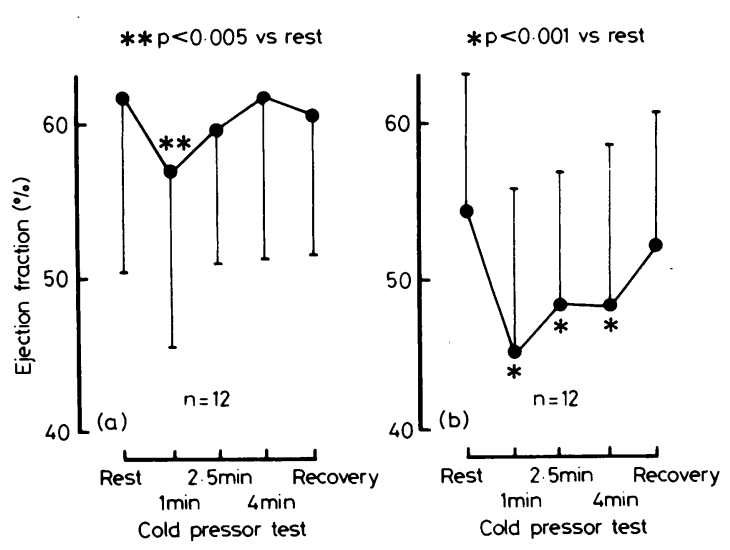

Fig. 3 Mean ( $\pm S D$ ) ejection fraction during the stages of cold pressor in (a) subjects with normal coronary arteries and (b) those with coromary disease. 
tion in the coronary disease group, no significant difference in the temporal behaviour of ejection fraction between the two groups was apparent statistically.

\section{RELATION BETWEEN HAEMODYNAMIC}

RESPONSES AND EJECTION FRACTION

As shown in Figs. 2 and 3 the maximum rise in mean systolic arterial pressure occurred at 2.5 minutes in both groups, whereas the maximum fall in mean ejection fraction occurred earlier at 1 minute. Individually, eight subjects without coronary disease showed their maximum fall in ejection fraction at 1 minute, and in five of these blood pressure had not yet peaked. In patients with disease, eight had their maximum fall in ejection fraction at 1 minute, and in seven of these systolic pressure had not yet peaked. This discordance between changes in function and changes in haemodynamic responses also applied when rate/ pressure double product was examined instead of pressure alone. In those without disease, five of the eight with a maximum fall in ejection fraction at 1 minute showed their maximal double product rise at 2.5 minutes. Six patients with coronary disease had a similar response.

\section{REGIONAL LEFT VENTRICULAR FUNCTION}

Fig. 4 shows the number of new regional abnormalities compared with those at rest at the various imaging stages for each of the two groups. Only one subject with normal coronary arteries showed a regional abnormality at rest. After 1 minute of cold pressor two normal volunteers and eight subjects with normal coronary arteries had developed abnormalities on the regional ejection fraction images, with a total of 12 new abnormal segments. Only one new regional abnormality remained after 2.5 minutes, two seg-

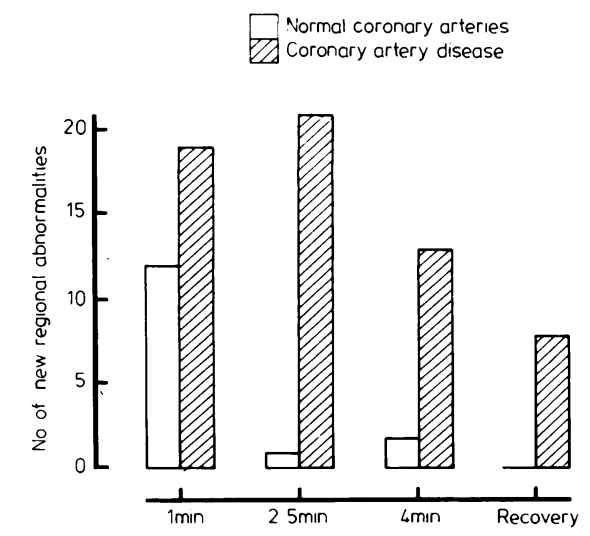

Fig. 4 Number of new regional abnormalities appearing at the different stages of cold pressor compared with the resting values, in each of the two groups. ments were present at 4 minutes, and after 2 minutes' recovery no regional abnormalities existed. Fig. 5a shows the sequence of images from a patient with normal coronary arteries. The regional ejection fraction images remained normal throughout. Although global ejection fraction fell at 2.5 minutes and at recovery, the values remained normal at all times. Fig. $5 \mathrm{~b}$ shows images from another patient with normal coronary arteries. In contrast to Fig. 5a, inferior and apical abnormalities are evident on the 1 minute image as well as a fall in global ejection fraction from $54 \%$ to $49 \%$. By 2.5 minutes, however, the ejection fraction returned to the resting value, and regional function has normal. Function remained normal on the subsequent images.

Seven patients with coronary disease had regional abnormalities at rest. Nineteen new segments appeared after 1 minute of cold pressor, 21 after 2.5 minutes, and 13 after 4 minutes, and 8 new segments were still apparent after 2 minutes' of recovery. Both patients with left main stem stenoses and one patient with triple vessel disease showed persistent abnormalities at recovery. Fig. $5 \mathrm{c}$ shows the images from a patient with triple vessel disease and a left main stem lesion. At rest, the apex shows reduced function at the site of a previous myocardial infarction. After 1 minute of cold stimulation, there was a pronounced fall in ejection fraction, and the regional ejection fraction image shows abnormalities throughout. The abnormalities persisted at 2.5 and 4 minutes, and, although ejection fraction rose to $45 \%$ after recovery, it remained depressed compared with values at rest, and there was persistent regional dysfunction in the inferior, apical, and anterior segments.

\section{Discussion}

The problems of motion artefact and of the relatively long time required for acquisition of an exercise MUGA study have prompted the search for alternative stress tests in patients with chest pain or coronary artery disease which do not require patient motion, effort, or motivation. The cold pressor test has been extensively investigated as such an alternative, although reports of the sensitivity and specificity of this test compared with dynamic exercise differ. ${ }^{1-5} 11$ The duration of imaging and the time of commencement of imaging vary from centre to centre, with some workers starting imaging 15 to $30 \mathrm{~s}$ after cold initiation with a 2 to 3 minute acquisition period, 3511 while Wainwright et al delayed the start of imaging for 1 minute and acquired data for 5 minutes. ${ }^{12}$ The results of our study using first pass radionuclide angiography and the short half life agent gold-195m indicate that left ventricular function does not remain stable during the cold pressor test. Rather, it appears 


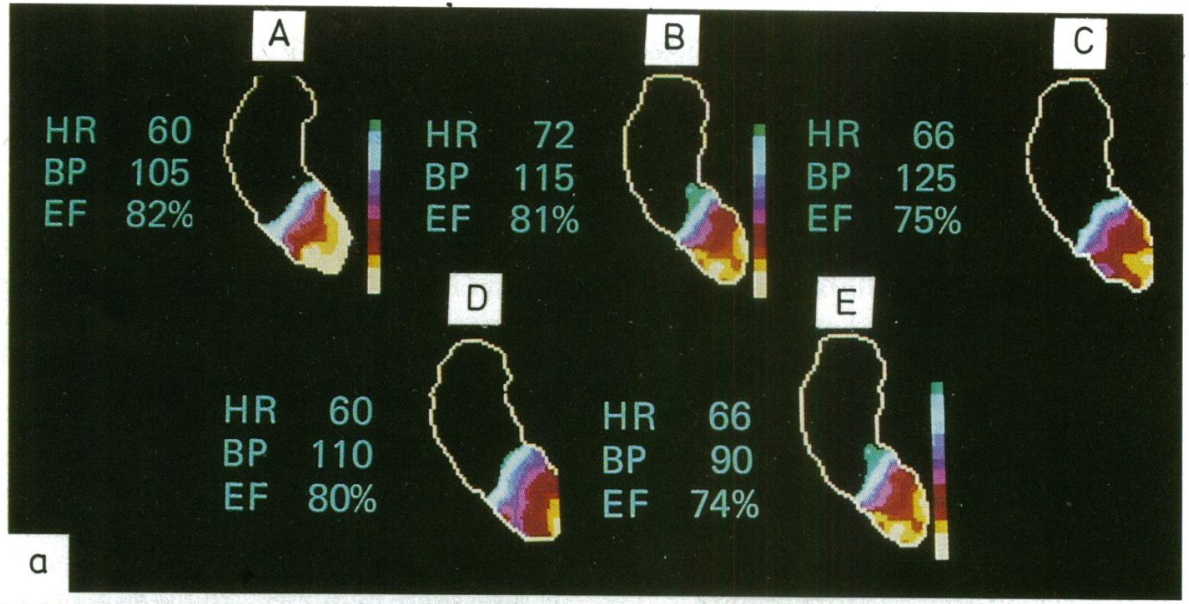

Fig. 5 Colour regional ejection fraction images from gold-195m studies, each with the end diastolic contour superimposed: (A) rest, (B) after 1 minute of cold pressor, (C) after 2.5 minutes, (D) after 4 minutes, and $(E)$ at recovery. (a) Shows images from a patient with normal coronary arteries, in whom regional function remained normal. (b) Shows images from another patient with normal coronary arteries. The 1 minute images $(B)$ show reduction of regional function inferiorly and apically, and ejection fraction has fallen; regional function and ejection fraction subsequently normalise. (c) Shows images from a patient with a left main stem stenosis. The rest images $(A)$ show reduced function at the apex in the site of a previous infarction. Global left ventricular dysfunction occurs after 1 minute $(B)$ and persists into the recovery period $(E)$. The 16 colour scale is shown next to three images. Yellow represents maximum regional ejection fraction, decreasing at $6.25 \%$ decrements through red, purple, blue, green, and black. HR, heart rate, BP, blood pressure, $E F$, ejection fraction. 
that ventricular function is depressed in most subjects during the early stages of cold stimulation but returns to normal rapidly in the absence of significant obstructive coronary artery disease. Multiple gated radionuclide studies will, therefore, acquire data not during a steady state but during a period of changing cardiac function. The resulting ejection fraction and images of regional wall motion will be integrals of a number of different functional states. This finding may help to explain the differences in reported results of cold pressor stimulation as a diagnostic test for coronary disease. The high sensitivity and specificity of the cold pressor test described by Wainwright $e t$ $a l^{12}$ may be related to the practice of delaying the start of imaging and imaging for a longer period, since subjects with normal arteries will be less likely to have abnormalities of function after the first minute.

The mechanisms for the induction of functional abnormalities by cold stimulation are complex. In patients with coronary disease, it is possible that the increase in myocardial oxygen demands due to an increase in arterial blood pressure and heart rate leads to ischaemia since demand exceeds a limited oxygen supply. It seems unlikely that this mechanism alone accounts for the observed abnormalities since the increments in the double product of heart rate and blood pressure ${ }^{13}$ were much smaller than those normally produced by bicycle exercise, and the ability of the latter to detect abnormalities of function is closely related to the adequacy of exercise and rise in double product. ${ }^{14}$ Although Neill et al failed to detect any changes in coronary vascular resistance induced by cold stimulation, ${ }^{15}$ Mudge et al clearly documented an increase in coronary vascular resistance during the cold pressor test in patients with coronary disease ${ }^{16}$ and showed an inappropriate reduction in coronary flow in some such patients. ${ }^{17}$ The calcium antagonist nifedipine has been shown to abolish the increase in coronary vascular resistance during the cold pressor test without affecting changes in left ventricular end diastolic pressure, ${ }^{18}$ and thus compression of intramural coronary vessels by the raised left ventricular end diastolic pressure is unlikely to be a mechanism for reduction in coronary flow. Similarly, a recent study by Goldhaber et al has shown that nifedipine prevents the cold pressor induced fall in ejection fraction in patients with coronary disease without significantly altering the double product. ${ }^{19}$ This drug may exert its beneficial effects by systolic unloading of the left ventricle or by inhibiting alpha mediated coronary vasoconstriction, which is thought to be calcium dependent.$^{20}$ Further support for the hypothesis that cold induced ischaemia is related to a reduction in supply through vasoconstriction rather than wholly to increased demand is found in the lack of temporal relation between the development of functional abnormalities and rise in systolic pressure. Our measurements were made using a cuff and not by means of an intra-arterial cannula, and therefore we cannot be exact as to the time of the peak blood pressure response, but Giles et al, using a non-imaging probe system and beat to beat ejection fraction measurements, reported a similar discordance between ejection fraction and blood pressure changes with the cold pressor test. ${ }^{21}$ Thus myocardial ischaemia during cold stimulation may result from an imbalance between oxygen supply and demand due to alterations in either variable.

The maintained depression of ejection fraction in patients with coronary disease and the very prolonged ischaemia seen in both the patients with left main stem stenosis and an additional patient with triple vessel disease are of interest. In the patient whose images are shown in Fig. 5c the double product was lower at recovery than at rest, and in the other two patients it was minimally higher than at rest. A previous study using positron tomography reported prolonged regional myocardial ischaemia for over $\mathbf{2 0}$ minutes after the cold pressor test in some patients with coronary disease, ${ }^{22}$ and it seems possible that in patients with severe coronary artery disease the mechanisms that lead to cold adaptation after some minutes ${ }^{6}$ are not enough to mitigate the profound ischaemia induced by cutaneous cold. This in turn may be related to the exaggerated myocardial release of $l$-noradrenaline that occurs in patients with coronary disease after cold stimulation ${ }^{23}$ and which could maintain reductions in regional myocardial perfusion and increases in oxygen demands ${ }^{23}$ despite peripheral adaptation to cold. Further investigations on a larger number of patients will be required before the diagnostic or prognostic use of the phenomenon of prolonged ischaemia will be apparent.

The population of patients with ischaemic symptoms in the absence of high grade obstructive coronary disease is a heterogeneous one, and various mechanisms for the clinical, electrocardiographic, and functional abnormalities have been suggested. ${ }^{24}$ Many such patients show abnormalities of left ventricular function on exercise. ${ }^{24} \mathrm{Half}$ of our patients without coronary disease showed early falls in ejection fraction, and most showed early regional abnormalities which returned to normal with time despite continuing cold stimulation, although the exact mechanism of cold adaptation is not clear. There is little previously reported information on the early response of normal volunteers or of patients with ischaemic syndromes and normal coronary arteries to cold pressor, but Stratton et al described a decrease in ejection fraction of $\geqslant 5 \%$ as common in normal subjects during the first minutes, ${ }^{25}$ and 9 of 11 normal subjects showed decreases in ejection fraction of a 
similar magnitude in the non-imaging probe study. ${ }^{21}$ Abnormalities in such patients cannot be related to limitations of oxygen supply caused by fixed coronary obstruction, and presumably the alpha mediated coronary vasoconstriction discussed earlier is important in producing such abnormalities. The possible role of focal coronary spasm in producing changes in ejection fraction and regional abnormalities is not yet clear. Raizner et al found that cold stimulation produced focal spasm in most patients with a precatheterisation diagnosis of variant angina and also in occasional patients with classical angina or atypical chest pain. ${ }^{26}$ All patients had atheromatous plaques at the site of the spasm. The same workers found a significant decrease in the luminal diameters of normal coronary arteries in all subgroups of patients after cutaneous cold. Their results differ from those of Feldman et al, who found no evidence of focal spasm in patients without variant angina, and only a minimal decrease in coronary diameter in normal and abnormal regions of the coronary tree. ${ }^{27}$ No provocation tests for coronary spasm were carried out in our patients with normal arteries at the time of angiography, but some of these subjects with ischaemic syndromes may have experienced spasm during the cold pressor test. In addition, possible changes in the coronary microcirculation could contribute more to changes in coronary vascular resistance than changes in epicardial vessels, ${ }^{27}$ but this possibility remains as yet uninvestigated.

The changes in ventricular function seen in two of the normal volunteers could also be related to transient changes in tone of large or small coronary vessels. The number of normal volunteers in the present study is too small to draw any firm conclusions about the frequency of cold induced abnormalities in such true normal subjects, and indeed further studies are required to investigate specifically whether normal volunteers react differently to cold from patients with normal coronary arteries and ischaemic syndromes.

One potential limitation of the study is the unknown contribution to the left ventricular functional changes of beta adrenergic blockade. Although no patient received medication on the day of the study, persistent pharmacological effects of beta blockade cannot be excluded, ${ }^{28}$ and this may have affected the response to cold. ${ }^{29}$

Our data have important clinical implications for both the conduct and interpretation of the cold pressor test when used with MUGA studies. Clearly, variations in timing and duration of imaging with this technique will affect the results since left ventricular function is not stable during the imaging period. If the aim is to detect coronary disease then it would seem prudent to delay the onset of imaging until after the first minute as normal subjects will be less likely to show abnormalities after this time. Prolonged ischaemia during the recovery period may be of some value in defining the extent of induced ischaemia.

\section{References}

1 Wainwright RJ, Brennand-Roper DA, Cueni TA, Sowton E, Hilson AJW, Maisey MN. Cold pressor test in detection of coronary heart disease and cardiomyopathy using technetium-99m gated blood pool imaging. Lancet 1979; ii: 320-3.

2 Wynne J, Holman BL, Mudge GH, Borow KM. Clinical utility of cold pressor radionuclide ventriculography in coronary artery disease [Abstract]. Am $\mathcal{F}$ Cardiol 1981; 47: 444.

3 Manyari DE, Nolewajka AJ, Purves P, Donner A, Kostuk WJ. Comparative value of the cold pressor test and supine bicycle exercise to detect subjects with coronary artery disease using radionuclide ventriculography. Circulation 1982; 65: 571-9.

4 McKillop JH, Tweddel AC, Martin W, Clark RS, Murray RG, Hutton I. Cold pressor radionuclide ventriculography-failure of global and regional left ventricular function changes to detect coronary artery disease [Abstract]. Nuclear Medicine Communications 1983; 4: 133.

5 Wasserman AG, Reiss L, Katz RJ, et al. Insensitivity of the cold pressor stimulation test for the diagnosis of coronary artery disease. Circulation 1983; 67: 1189-93.

6 Greene MA, Boltax AJ, Lustig GA, Rogow E. Circulatory dynamics during the cold pressor test. Am $\mathcal{f}$ Cardiol 1965; 16: 54-60.

7 Dymond DS, Jarritt PH, Britton KE, Spurrell RAJ. Detection of postinfarction left ventricular aneurysms by first pass radionuclide ventriculography using a multicrystal gamma camera. Br Heart f 1979; 41: 68-78.

8 Elliott AT, Dymond DS, Stone DL, et al. A Hg-195m/ Au-195m generator for use in first pass nuclear angiocardiography. Phys Med Biol 1983; 28: 139-47.

9 Dymond DS, Elliott AT, Flatman W, et al. The clinical validation of gold-195m: a new short half-life radiopharmaceutical for rapid, sequential, first pass angiocardiography in patients. $\mathcal{F}$ Am Coll Cardiol 1983; 2: 85-92.

10 Maddox DE, Holman BL, Wynne J, et al. Ejection fraction image: a non-invasive index of regional left ventricular wall motion. Am $\mathcal{Y}$ Cardiol 1978; 41: 1230-8.

11 Verani MS, Zacca NM, DeBauche TL, Miller RR, Chahine RA. Comparison of cold pressor and exercise radionuclide angiocardiography in coronary artery disease. F Nucl Med 1982; 23: 770-6.

12 Wainwright RJ, Brennand-Roper DA, Maisey MN, Sowton E. Cold pressor radionuclide ventriculography. In: Salvatore M, Porta E, eds. Radioisotopes in cardiology. New York: Plenum Press, 1983: 101-13.

13 Gobel FL, Nordstrom LA, Nelson RR, Jorgensen CR, Wang $Y$. The rate-pressure product as an index of myocardial oxygen consumption during exercise in patients with angina pectoris. Circulation 1978; 57: 549 56.

14 Brady TJ, Thrall JH, Lo K, Pitt B. The importance of adequate exercise in the detection of coronary heart dis- 
ease by radionuclide ventriculography. 7 Nucl Med 1980 ; 21: 1125-30.

15 Neill WA, Duncan DA, Kloster F, Mahler DJ. Response of coronary circulation to cutaneous cold. $A m \mathcal{F}$ Med 1974; 56: 471-6.

16 Mudge GH Jr, Grossman W, Mills RM Jr, Lesch M, Braunwald E. Reflex increase in coronary vascular resistance in patients with ischemic heart disease. $N$ Engl $\mathcal{F}$ Med 1976; 295: 1333-7.

17 Mudge GH, Goldberg S, Gunther S, Mann T, Grossman W. Comparison of metabolic and vasoconstrictor stimuli on coronary vascular resistance in man. Circulation 1979; 59: $544-50$.

18 Gunther S, Green L, Muller JE, Mudge GH, Grossman W. Prevention by nifedipine of abnormal coronary vasoconstriction in patients with coronary artery disease. Circulation 1981; 63: 849-55.

19 Goldhaber SZ, White HD, Holman BL, et al. Prevention by nifedipine of cold pressor-induced decrease in left ventricular ejection fraction. $\mathcal{F}$ Am Coll Cardiol 1983; 1: 1512-7.

20 van Breemen C, Siegel B. The mechanism of alphaadrenergic activation of the dog coronary artery. Circ Res 1980; 46: 426-9.

21 Giles R, Marx P, Commerford P, Zaret B, Berger HJ. Rapid sequential changes in left ventricular function during cold pressor and isometric handgrip: relationship to blood pressure and mechanistic implications [Abstract]. Am $\mathcal{F}$ Cardiol 1982; 49: 1002.

22 Selwyn AP, l'Abbate A, Allan RM, Horlock P, Maseri A. Prolonged myocardial ischaemia after cold pressor test; detection of ischaemia using positron tomography
[Abstract]. Br Heart F 1981; 45: 342.

23 Mueller HS, Rao PS, Rao PB, Gory DJ, Mudd JG, Ayres SM. Enhanced transcardiac 1-norepinephrine response during cold pressor test in obstructive coronary artery disease. Am f Cardiol 1982; 50: 1223-8.

24 Berger HJ, Sands MJ, Davies RA, et al. Exercise left ventricular performance in patients with chest pain, ischemic-appearing exercise electrocardiograms, and angiographically normal coronary arteries. Ann Intern Med 1981; 94: 186-91.

25 Stratton JR, Halter JB, Hallstrom AP, Caldwell JH, Ritchie JL. Comparative plasma catecholamine and haemodynamic responses to handgrip, cold pressor and supine bicycle exercise testing in normal subjects. $\mathcal{F} \mathrm{Am}$ Coll Cardiol 1983; 2: 93-104.

26 Raizner AE, Chahine RA, Ishimori T, et al. Provocation of coronary artery spasm by the cold pressor test: hemodynamic, arteriographic and quantitative angiographic observations. Circulation 1980; 62: 925-32.

27 Feldman RL, Whittle JL, Marx JD, Pepine CJ, Conti CR. Regional coronary hemodynamic responses to cold stimulation in patients without variant angina. Am $\mathcal{F}$ Cardiol 1982; 49: 665-73.

28 Lindenfeld J, Crawford MH, O'Rourke RA, Levine SP, Montiel MM, Horwitz LD. Adrenergic responsiveness after abrupt propranolol withdrawal in normal subjects and in patients with angina pectoris. Circulation 1980; 62: 704-11.

29 Kern M, Ganz P, Horowitz J, Mudge GH Jr, Grossman W. Potentiation of coronary vasoconstriction by betaadrenergic blockade [Abstract]. Circulation 1981: 64 suppl IV: 82. 